\title{
Evaluation of Potential Drug Interactions and Related Factors in Patients Admitted in Department of Cardiology of Farshchian Heart Hospital of Hamadan
}

\author{
Maryam Torkashvand ${ }^{1}$, Farzaneh Esnaashari², Maryam Mehrpoya ${ }^{3}$, Farnaz Fariba ${ }^{4}$, \\ Forough Nadi $^{1}$, Fatemeh Zeraati ${ }^{5,6, *}$
}

${ }^{1}$ General Practitioner, Hamadan University of Medical Sciences, Hamadan, Iran

${ }^{2}$ Associate Professor, Department of Social Medicine, School of Medicine, Hamadan University of Medical Sciences, Hamadan, Iran

${ }^{3}$ Assistant Professor, Department of clinical Pharmacology, School of Pharmacy, Hamadan University of Medical Sciences, Hamadan, Iran

${ }^{4}$ Associate Professor, Department of Cardiology, School of Medicine, Hamadan University of Medical Sciences, Hamadan, Iran

${ }^{5}$ Professor of Pharmacology, Medicinal Plants \& Natural Products Research Center, Hamadan University of Medical Sciences, Hamadan, Iran

${ }^{6}$ Professor, Department of Pharmacology \& Toxicology, School of Pharmacy, Hamadan University of Medical Sciences, Hamadan, Iran

* Corresponding Author: Fatemeh Zeraati, Department of Pharmacology and Toxicology, School of Pharmacy, Hamadan University of Medical Sciences, Hamadan, Iran.Email: zeraati@umsha.ac.ir

Received: 21.04 .2018

Accepted: 14.08 .2018

How to Cite this Article:

Torkashvand M, Esnaashari F, Mehrpoya M, Fariba F, Nadi F, Zeraati F. Evaluation of Potential Drug Interactions and Related Factors in Patients Admitted in Department of Cardiology of Farshchian Heart Hospital of Hamadan. Avicenna J Clin Med. 2018; 25(2): 105-111. DOI: 10.21859 /ajcm.25.2.105

\section{Abstract}

Background and Objective: Cardiovascular patients are susceptible to drug interactions due to the simultaneous use of several drug types. The purpose of this descriptive-analytic study was to evaluate the potential drug interactions and the related factors in subjects admitted to the Cardiology Department of Farshchian heart hospital of Hamadan, Iran.

Materials and Methods: This descriptive cross-sectional study was conducted on 900 subjects. The data, including drugs, sex, type of illness, and length of hospitalization were extracted from files of the patients referred to Farshchian hospital in 2014 and 2015. Drug interactions were evaluated by the Micromedex 1630. The results were analyzed using SPSS software (version 16).

Results: Of the 900 cases, 424 (47.1\%) were male and 476 (52.9\%) were female. A total of 4318 cases of interference were detected, 1610 (37.3\%) of which were strongly interfered and 2708 (62.7\%) were moderately interfered. The mean ages of males and females were 61.00 and 60.50 years, respectively ( $\mathrm{P}=0.602)$. It was reported that $815(90.6 \%)$ cases had at least one interaction. Based on the results, 389 male patients (91.3\%) and 426 (90.6\%) female patients had a drug interaction $(\mathrm{P}=0.258)$. The differences of mean age, number of drugs, and length of hospitalization were statistically significant between the groups with and without interactions $(\mathrm{P}=0.001)$. The highest frequency of drug-drug interaction was detected with moderate severity in atrovastatin and clopidogrel with 464 repetition times. Furthermore, aspirin and clopidogrel with major severity and 485 repetitions were reported the most interfering drugs.

Conclusion: Based on the results of this study, the amount of drug intake, length of hospitalization, and sex affect the incidence of drug interactions.

Keywords: Cardiovascular Diseases, Drug-Drug Interactions, Risk Factors 
dof: $10.21859 /$ ajcm.25.2.105

\title{
ارزيابى تداخلات دارويى بالقوه و فاكتورهاى مرتبط با آن در بيماران بسترى در بخش قلب و عروق بيمارستان قلب فرشيحيان هملان
}

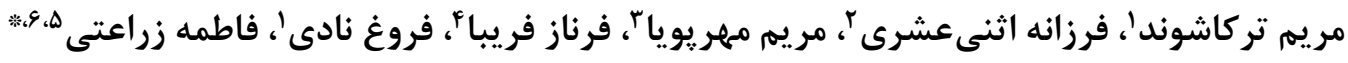 \\ ' دكتراى حرفهاى يزشكى، دانشخاه علوم يزشكى همدان، همدان، ايران

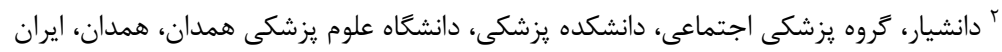

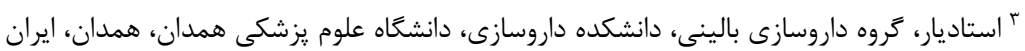

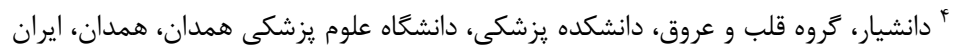

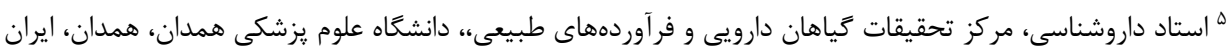

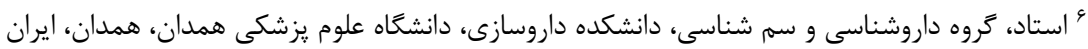 \\ * نويسنده مسئول: فاطمه زراعتى، كروه داروشناسى و سمشناسى، دانشكده داروسازى، دانشخاه علوم يزشكى همدان، همدان، ايران. \\ ايميل:zeraati@umsha.ac.ir
}

\begin{tabular}{|c|c|}
\hline 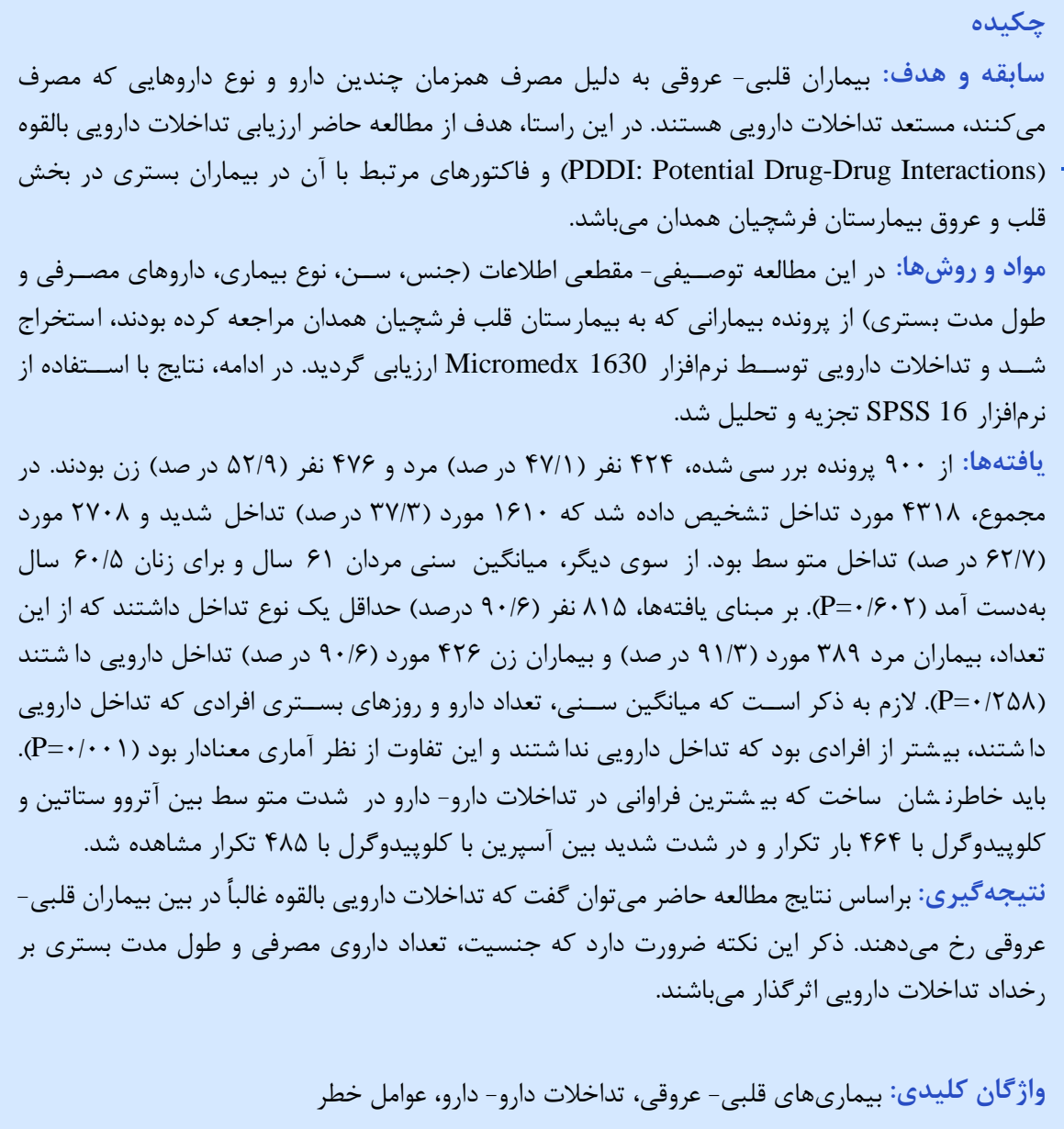 & 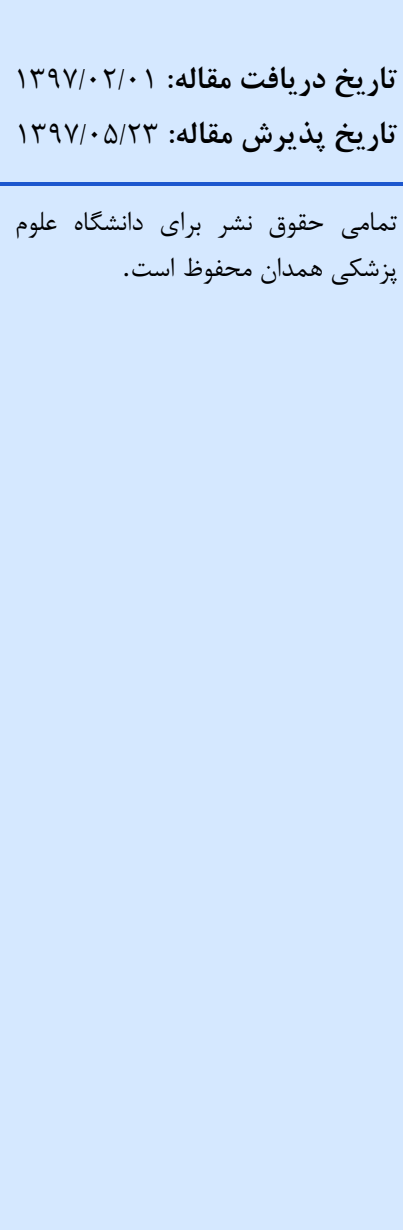 \\
\hline
\end{tabular}

مقلدمه

نظر اثرات در مانى و يا ايججاد عوارض تحت تأثير داروى ديخر

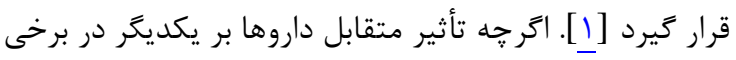

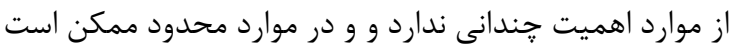

تداخلات دارويى بالقوه يكى از مهممترين موارد خطاهاى

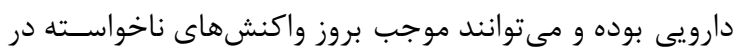

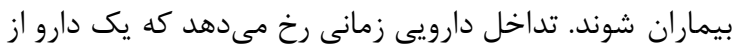


مىشوند، بر آن شديم تا مطالعه حاضر را انجام دهيم. اميدواريم

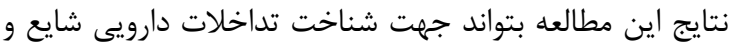

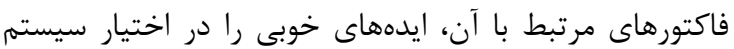

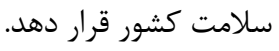

\section{مواد و روشها}

مطالعه توصــيفى - مقطعى حاضـــر در ارتباط با بيماران بســرى در بيمارســان قلب و عروق فرشـجـيان همدان انجام شد. يس از تعيين حجم نمونه توسط محاسبات آمارى و توجها

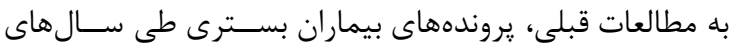

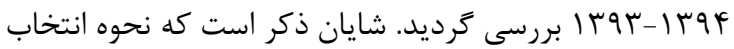
نمونهها به صورت تصادفى بود. يروندههاى بيمارانى كه حداقل

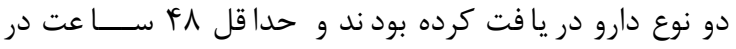

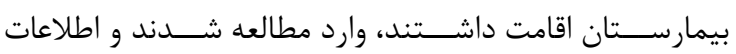

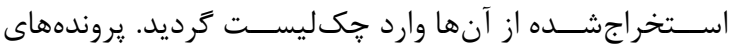

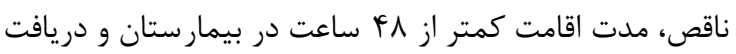
كمتر از دو نوع دارو بهعنوان معيارهاى خروج از مطالعه در نظر كرفته شدند.

SPSS دادها يس از جمعآورى با استفاده از نرمافزار 16 تجزيه و تحليل شدند. براى توصيف دادههاى كمى از ميانگين و

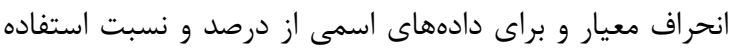

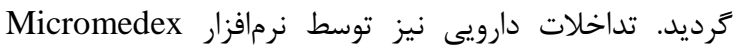

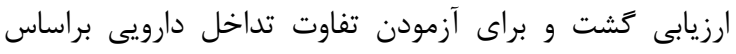

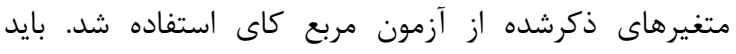

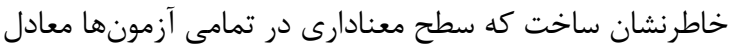
ه درصد در نظر گرفته شد.

\section{يافته ها}

در اين مطالعه يرونده . .9 بيمار كه شرايط ورود به مطالعه را داشتند مورد ارزيابى قرار گرفت.

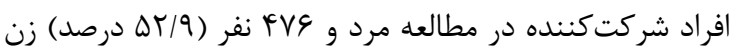

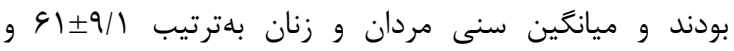

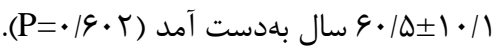

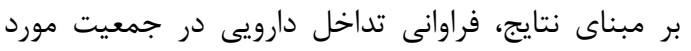

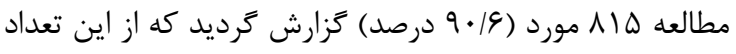

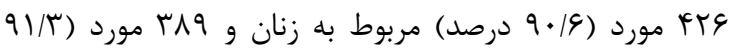

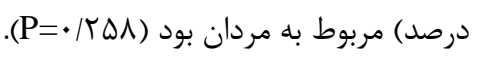

در جدول ا نتايج مقايسه بين بيماران با تداخل دارويى و ودردان

$$
\text { بدون آن نشان داده شده است. }
$$

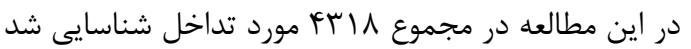

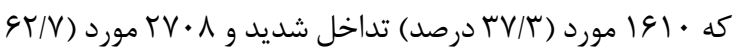
درصد) تداخل متوسط بود. در جداول r و ب فراوانى بروز تداخل متوسط و ود شديد به تفكيك داروهاى مصرفى ارائه شده است.
در را ستاى اهداف درمانى و سودمند با شد؛ اما در موارد قابل

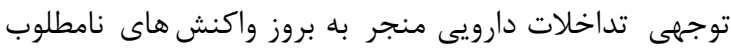

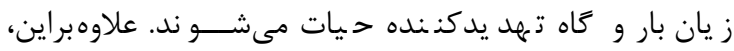

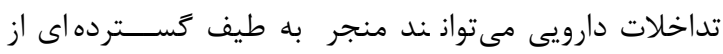

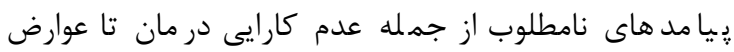

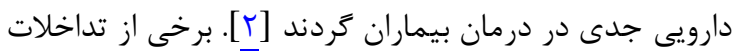

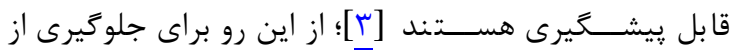

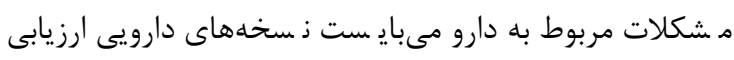

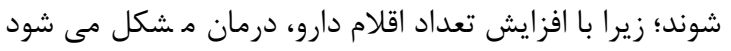

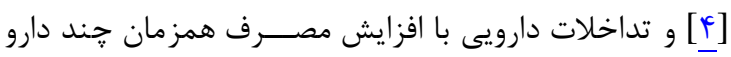

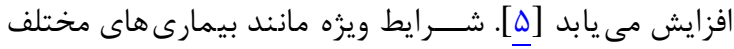
همزمان، بيمارى هاى مزمن و ويلىفارماسى (Polypharmacy)

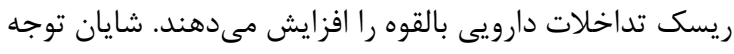

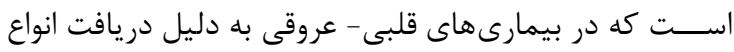

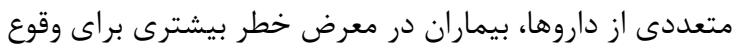
تداخلات دارويى قرار دارند. نتايج تداخلات دارويى طيف وسيعى دارد و دربر دريرنده

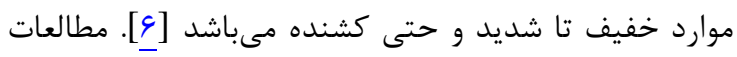

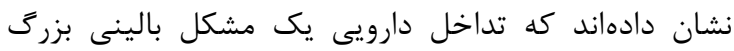

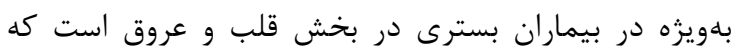

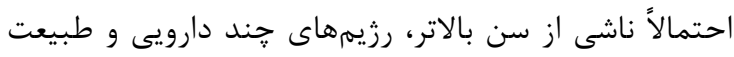

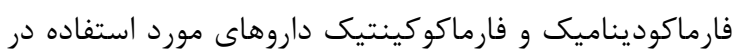

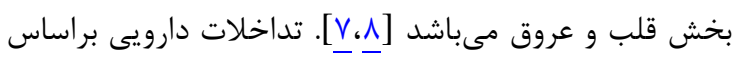

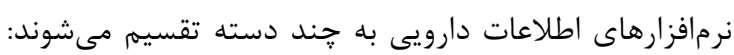

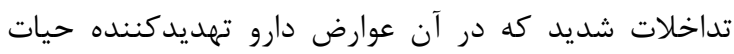

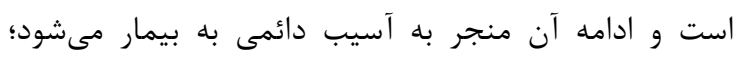

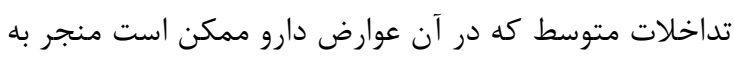

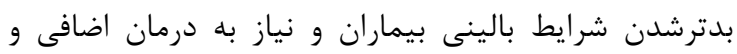

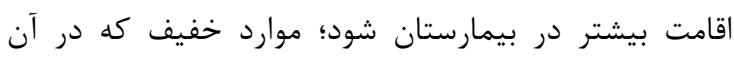

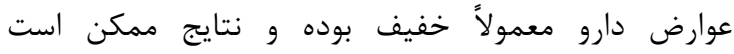

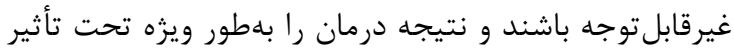

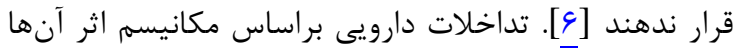

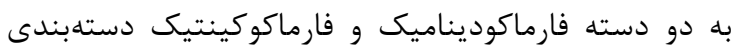
مىشوند. در تداخل فارماكوكينتيك جذب، توزيع، متابوليسم

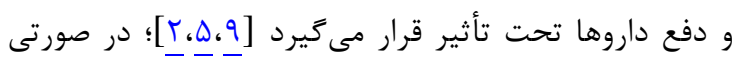

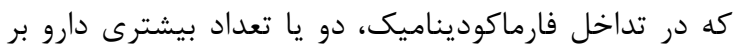

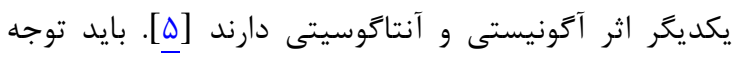

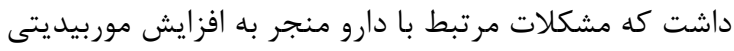

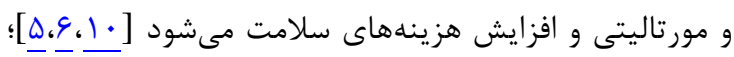

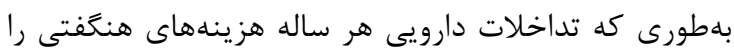

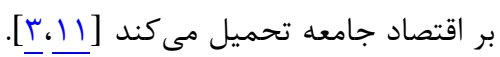

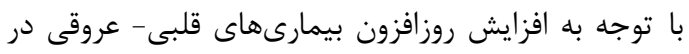

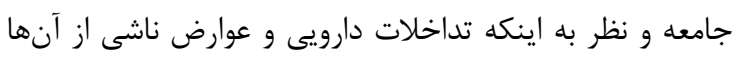
منجر به تحميل بار مالى فراوانى بر سيستم سلامت كشور 
جدول ا: ميانگين متغيرها براساس بروز تداخل

\begin{tabular}{|c|c|c|c|}
\hline \multirow{2}{*}{ سطح معنادارى } & \multicolumn{2}{|c|}{ 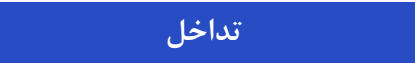 } & \\
\hline & ندارد & دارد & \\
\hline $.1 \cdot 19$ & $\Delta \Lambda / \pm 1 \cdot / 1$ & $9 / / 1 \pm 9 / 1$ & سن بيمار (سال) \\
\hline$\cdot 1 \cdot \cdot 1$ & $\Delta / r T \pm Y / \Lambda$ & $V / r \pm r / \varepsilon \Delta$ & تعداد داروى مصرفى \\
\hline$\cdot 1 \cdot \cdot 1$ & $F / T \varphi \pm 1 / 9$ & $\Delta / 1 \varphi \pm r / F F$ & تعداد روزهاى بسترى \\
\hline
\end{tabular}

جدول r: فراوانى بروز تداخل متوسط در داروهاى مصرفى بيماران

\begin{tabular}{|c|c|c|}
\hline درصد & فراوانى & تداخل \\
\hline$|V /|$ & fat & آتوروستاتين / كلوِيدوكرل \\
\hline $1 \Delta / V$ & FTD & آسيرين / متويرولول \\
\hline $\mid \psi /$. & rVA & آسيرين / نيتروكانتين \\
\hline $9 / V$ & INT & آسيرين / آميلوديبين \\
\hline$\Delta / 9$ & 181 & آسيرين / اسِيرنولاكتون \\
\hline$\Delta / \Delta$ & $10 \cdot$ & آسيرين / فورزمايد \\
\hline$f / q$ & rזו & آسيرين / كلىبنكلاميد \\
\hline$\mu / r$ & 119 & آميلوديِين / متويرولول \\
\hline$r / V$ & 99 & آسيرين/ ديلتيازم \\
\hline$r / \mathcal{F}$ & 99 & آسيرين / هيدروكلروتيازيد \\
\hline$r / F$ & $g t$ & آسيرين / لوزار تان \\
\hline $1 / r$ & זr & كايتويريل / حَلىبنـكلاميد \\
\hline $1 / T$ & זr & حَلىبنكلاميد / متويرولول \\
\hline $1 / 1$ & r & لوزار تان / اسِيرنولاكتون \\
\hline $1 / 1$ & $r q$ & آسيرين / والزارتان \\
\hline$\cdot 19$ & IV & آسيرين / كاروديلول \\
\hline $.11 \cdots$ & $r V \cdot \Lambda$ & جمع \\
\hline
\end{tabular}

جدول ب: فراوانى بروز تداخل شديد در داروهاى مصرفى بيماران

\begin{tabular}{|c|c|c|}
\hline درصد & فراوانى & 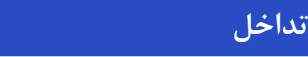 \\
\hline tN/F & FAD & آسيرين / كلوييدوكرل \\
\hline$r \cdot / f$ & rrq & آسيرين / هيارين \\
\hline$I T / F$ & 199 & هيارين / كلوييدوكرل \\
\hline $1 T / 4$ & 191 & آميلودييين / كلو ييدوگرل \\
\hline$|r /|$ & 194 & آسيرين / انوكسايارين \\
\hline$F / T$ & qV & كلو ييدوكر ل / انوكسايارين \\
\hline$\varphi / 1$ & 99 & ديلتيازم/ آترووستاتين \\
\hline$r / l$ & r & كايتويريل / لوزارتان \\
\hline$r / 1$ & זr & وارفارين / انوكسا يارين \\
\hline$r / 1$ & r & هيارين / نيتروكانتين \\
\hline$\cdot 11 \cdots$ & $|8|$. & جمع \\
\hline
\end{tabular}

قلبى (CAD: Coronary Artery Disease) بر شدت تداخل تأثير مى كذارند (جدول (l).
با انجام آناليز رگرسيون لجستيك مشخص گرديد كه

جنسيت زن، تعداد بالاتر اقلام مصرف دارو و بيمارى زمينام زجينهاى 
جدول fا: ارتباط بين متغيرهاى مورد مطالعه و شدت تداخل

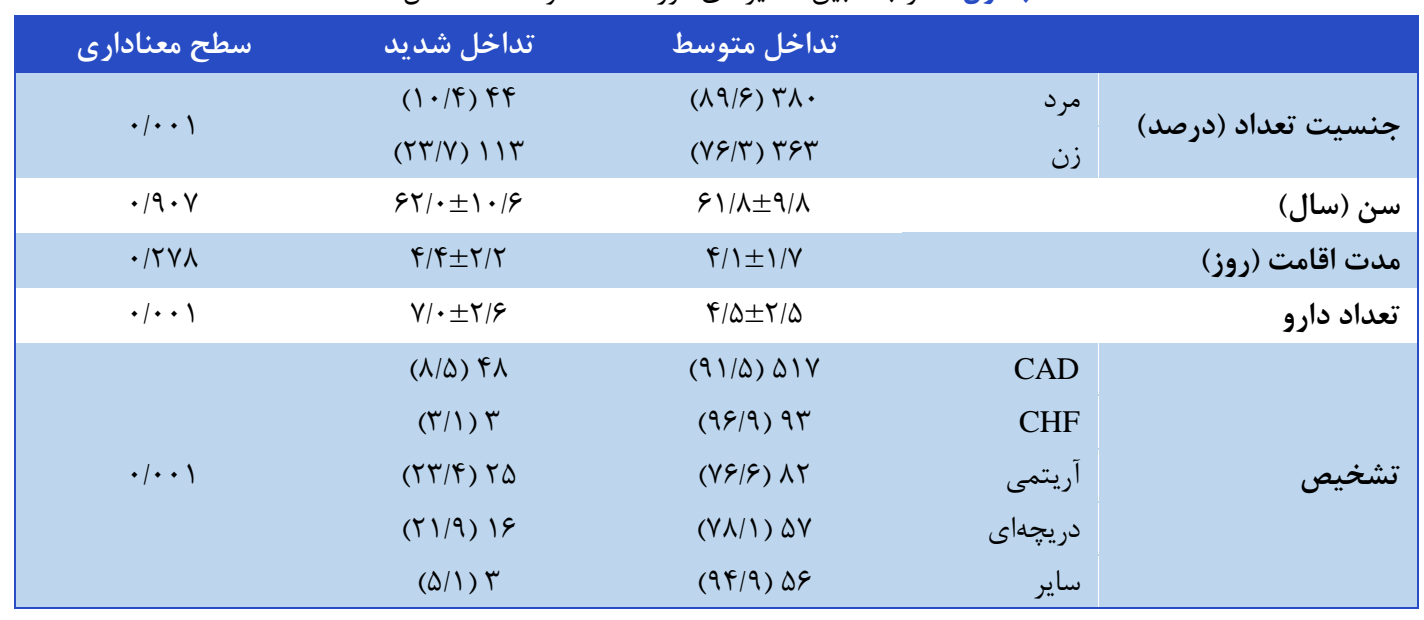

تداخل متوسط از تداخل شديد بيشتر مىباشد. در مطالعه مرتضى

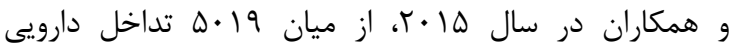

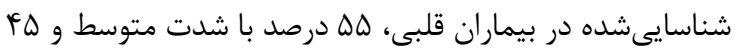
درصد با شدت شديد تشخيص داده شدند [ع] فئ.

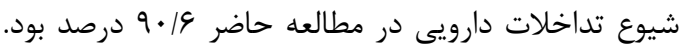

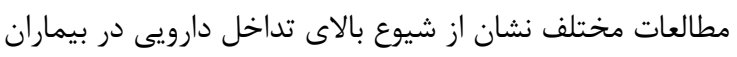

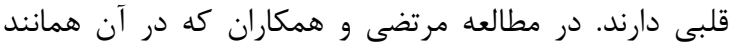

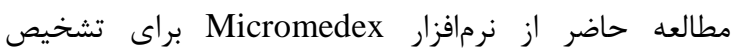
تداخلات دارويى استفاده شده بود،

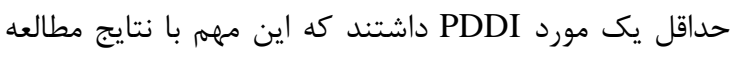
حاضر همسو مىباشد. علت شيوع متفاوت تداخلات دارويى در

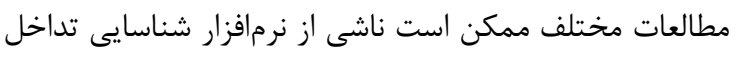

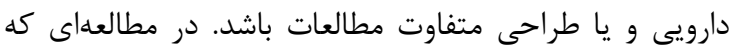

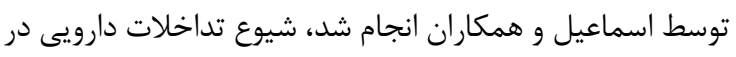

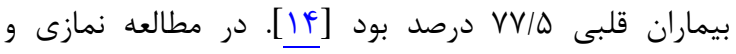

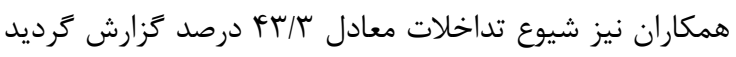

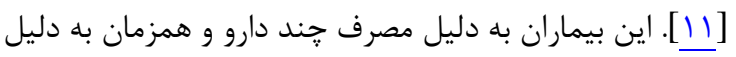

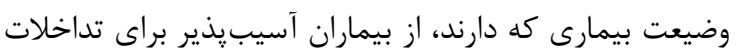

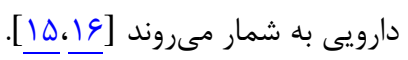

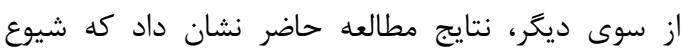
تداخلات در افرادى كه ميانگين سنى بيشترى دارند، بيشتر است دأن

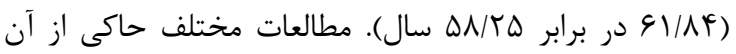

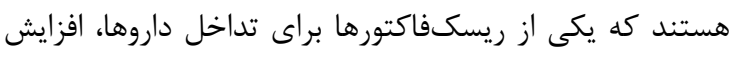

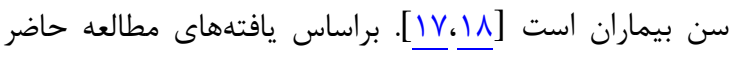

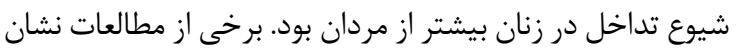

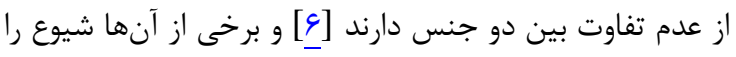

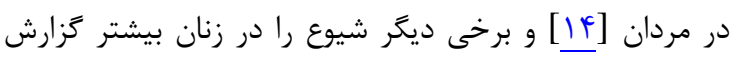

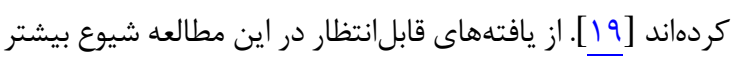

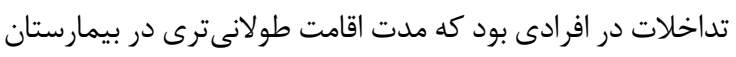
داشتند. بر مبناى نتايج، ميانكين روزهاى بسترى درى در افرادى كه دادي

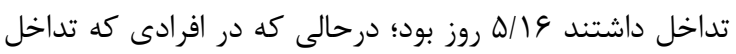

مطالعات كذشته نشان دادهاند كه بيماران قلبى - عروقى در

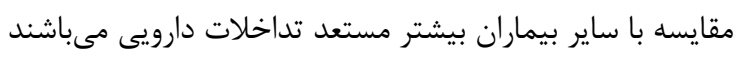

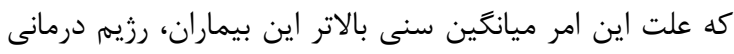

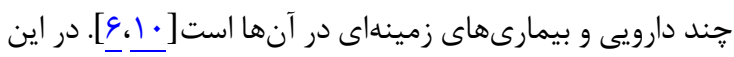

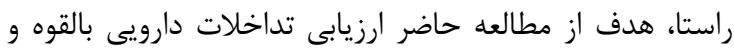

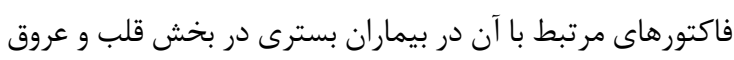

$$
\text { بيمارستان فرشجيان همدان بود. }
$$

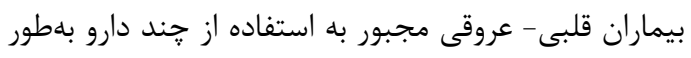

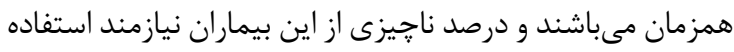

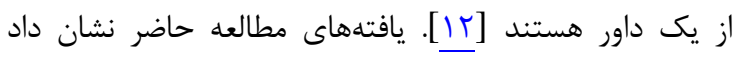

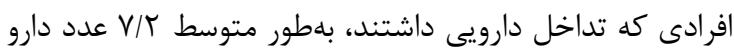

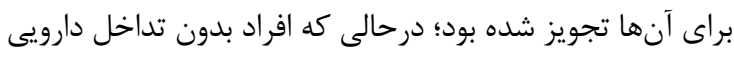

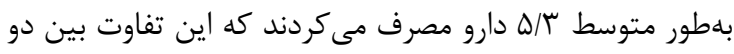

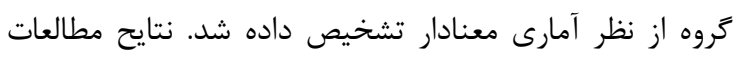
حذشته نيز از اين يافته مطالعه حاضر حمايت ميى كنند؛ بلهطور

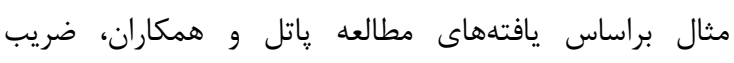

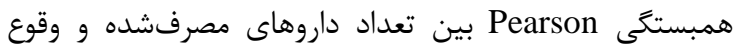

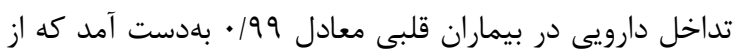

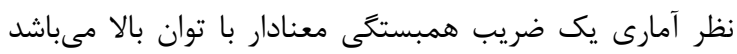
[ه]]. هنكامى كه بيش از يكى نوع دارو در رزيم درمانى اين بيماران

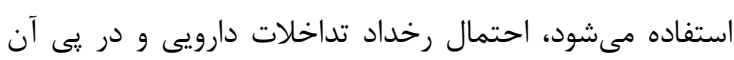

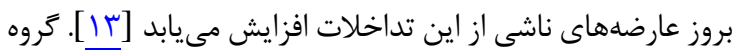

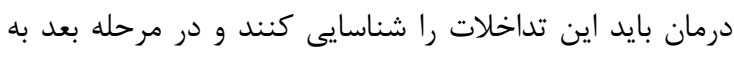

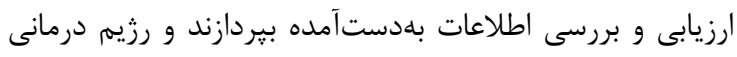
مؤثر با كمترين عارضه و تداخل را براى بيماران تجويز نمايند.

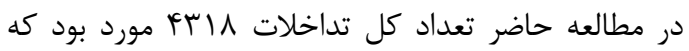

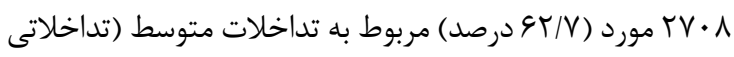
كه لازم است بيماران توسط كادر درمان پايش شوند) و • •

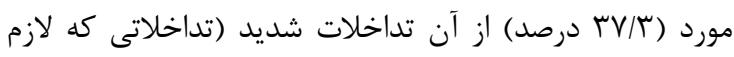

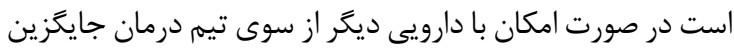

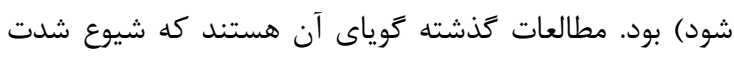


مىباشد [ه].

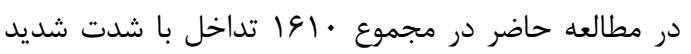

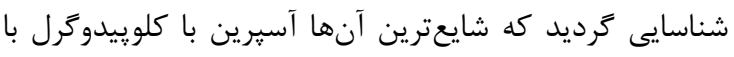

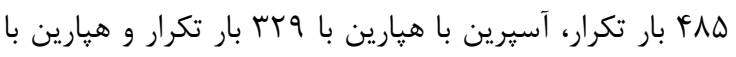
كلوييدو

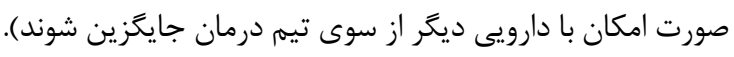

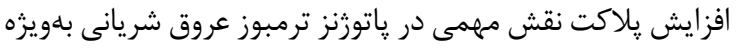

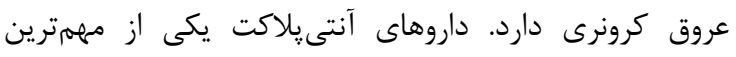

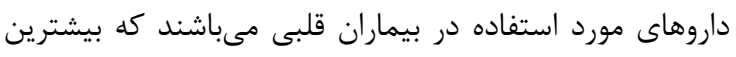

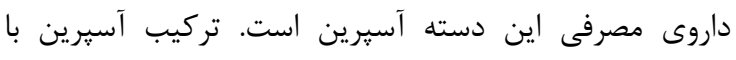

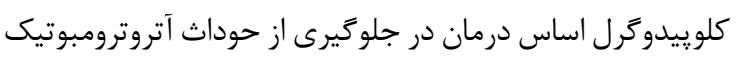

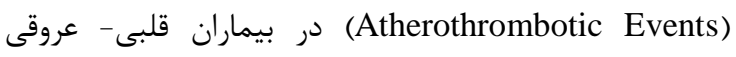
مىباشد و راهنماهاى موجود استفاده از اين داروها در بيمان بيماران

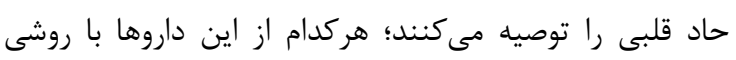

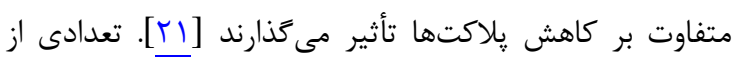

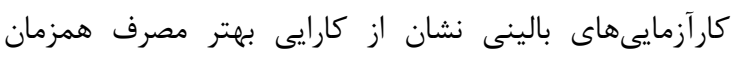

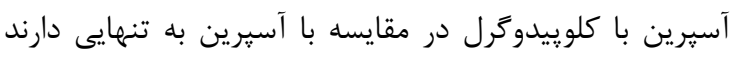

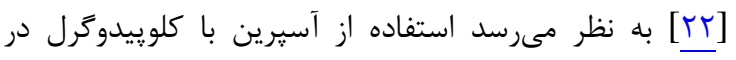

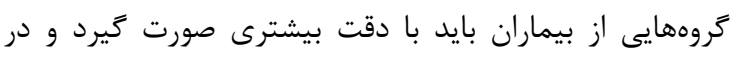

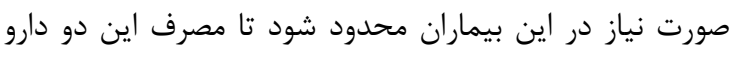
همزمان با هم در تمام بيماران قلبى - عروقى محدود كردد [بردئ.

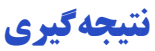

در اين مطالعه نتايج كارآمدى از بررسى رابطه جنس بيمار ان،

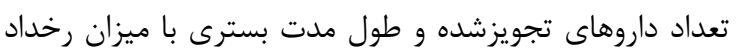

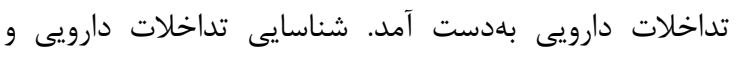

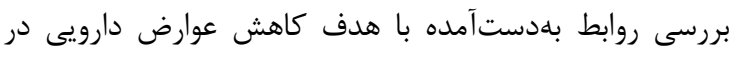

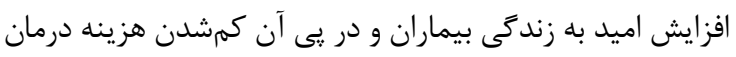

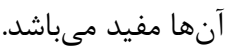

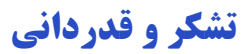

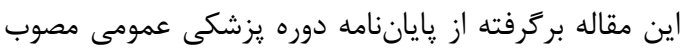

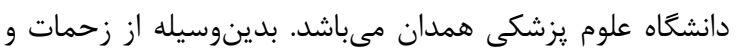

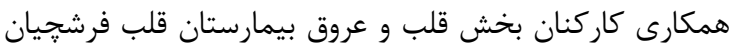

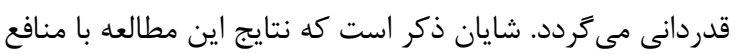

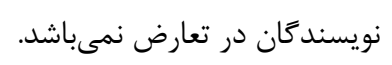

\section{REFERENCES}

1. Rahimi B, Gharabaghi N, Hesari Z, Balanji S, Alinia T. Prevalence of potential drug interactions in patients in the intensive care unit of Urmia Taleghani hospital. Urmia Med J. 2013;24(2):133-45. [Persian]

2. Rafeian M. Drug interactions in internal and surgical wards of Kashani Hospital, Shahrekord, 1997. Tehran Univ Med J. 2001;59(4):86-91. [Persian]

3. Namazi S, Pourhatami S, Borhani-Haghighi A, Roosta S. Incidence of potential drug-drug interaction and related factors in hospitalized neurological patients in two Iranian teaching hospitals. Iran J Med Sci. 2014;39(6):515-21. PMID: 25429173
نداشتند، ميانگين روزهاى بسترى كمتر و برابر با ع/T ع روز

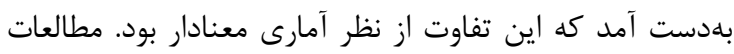

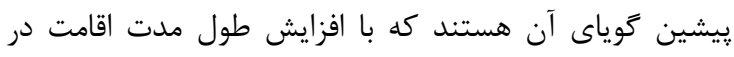

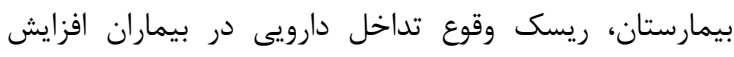

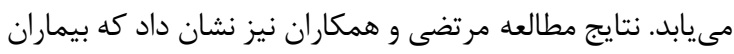
مسنتر با مدت اقامت بيشتر در بيمارستان و افزايش تعداد

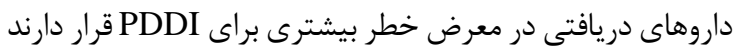
كه اين مهمم با يافتههاى مطالعه حاضر همسو مي دياشد.

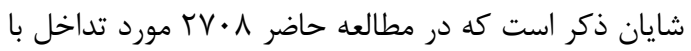

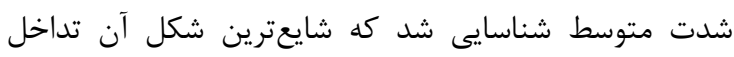

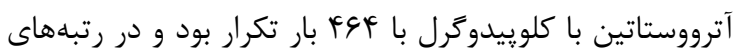

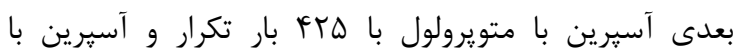

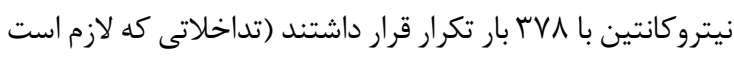

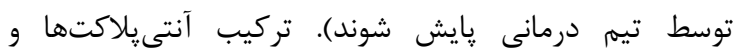

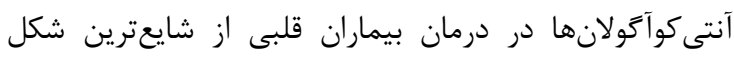

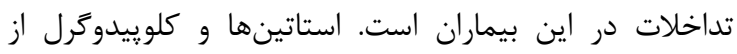
يرمصرفترين داروهاى بيماران قلبى مئباشند كه بـ به دليل

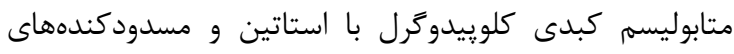

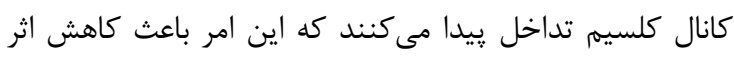

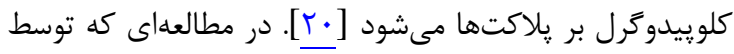

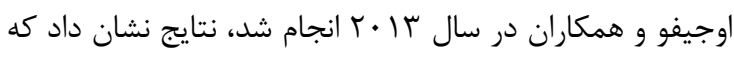

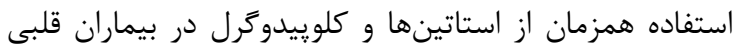
نمىتواند يك تداخل مههم تلقى شود كه اين يافته با نتايج مطالعه دئه

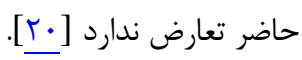

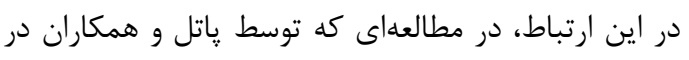

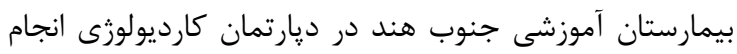

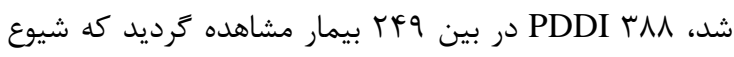

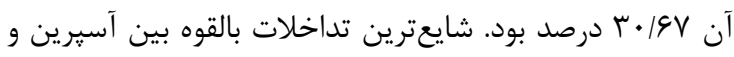

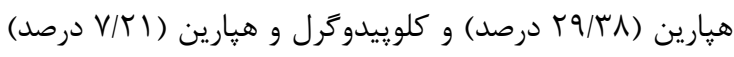
بdدست آمد. دستهاى دارويى كه تداخل در بين آنهارئ دردا مشاهده

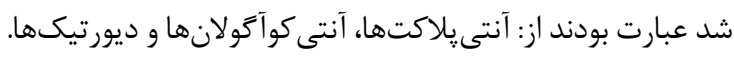

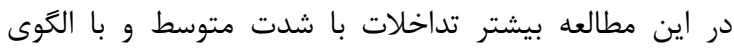

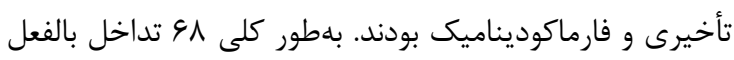

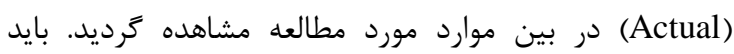

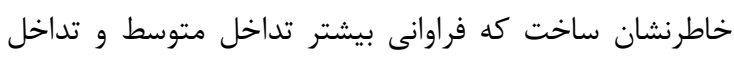

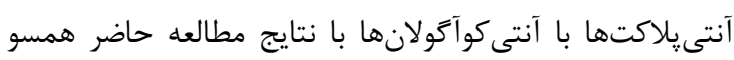

4. Ahmad A, Khan MU, Haque I, Ivan R, Dasari R, Revanker $\mathrm{M}$, et al. Evaluation of potential drug-drug interactions in general medicine ward of teaching hospital in southern India. J Clin Diag Res. 2015;9(2):FC10-3. PMID: 25859467 DOI: 10.7860/JCDR/2015/11264.5608

5. Patel VK, Acharya LD, Rajakannan T, Surulivelrajan M, Guddattu V, Padmakumar R. Potential drug interactions in patients admitted to cardiology wards of a south Indian teaching hospital. Australas Med J. 2011;4(1):9-14. PMID: 23393498 DOI: 10.4066/AMJ.2011.450

6. Murtaza G, Khan MY, Azhar S, Khan SA, Khan TM. Assessment of potential drug-drug interactions and its 
associated factors in the hospitalized cardiac patients. Saudi Pharm J. 2015;24(2):220-5. PMID: 27013915 DOI: 10.1016/j.jsps.2015.03.009

7. Passarelli MCG, Jacob-Filho W, Figueras A. Adverse drug reactions in an elderly hospitalised population. Drugs Aging. 2005;22(9):767-77. PMID: 16156680

8. Uijtendaal EV, van Harssel LL, Hugenholtz GW, Kuck EM, Zwartvan Rijkom JE, Cremer OL, et al. Analysis of potential drug-drug interactions in medical intensive care unit patients. Pharmacotherapy. 2014;34(3):213-9. PMID: 24390929 DOI: 10.1002/phar.1395

9. Rafieii H, Arab M, Ranjbar H, Arab N, Sepehri G, Amiri M. The prevalence of potential drug interactions in Intensive Care Units. Iran J Crit Care Nurs. 2012;4(4):191-6.

10. Karimzadeh I, Namazi S, Shalviri G, Gholami K. Cardiovascular drug adverse reactions in hospitalized patients in cardiac care unit. Afr J Pharm Pharmacol. 2011;5(4):493-9. DOI: 10.5897/AJPP10.413

11. Namazi S, Moosavi N. The evaluation and management of drug-drug interactions in patients on cardiovascular and cardiosurgery wards in Namazi and Shahid Faghihi hospitals, Iran, Shiraz. Res Pharm Sci. 2012;7(5):911.

12. Mukete BN, Ferdinand KC. Polypharmacy in older adults with hypertension: a comprehensive review. J Clin Hypertens (Greenwich). 2016;18(1):10-8. PMID: 26215211 DOI: 10.1111/jch.12624

13. Roblek T, Deticek A, Leskovar B, Suskovic S, Horvat M, Belic A, et al. Clinical-pharmacist intervention reduces clinically relevant drug-drug interactions in patients with heart failure: A randomized, double-blind, controlled trial. Int J Cardiol. 2016;203:647-52. PMID: 26580349 DOI: 10.1016/j.ijcard.2015.10.206

14. Ismail M, Iqbal Z, Khattak MB, Khan MI, Javaid A, Khan TM. Potential drug-drug interactions in cardiology ward of a teaching hospital. Health Med. 2012;6(5):1618-24.

15. Smithburger PL, Kane-Gill SL, Seybert AL. Drug-drug interactions in cardiac and cardiothoracic intensive care units: an analysis of patients in an academic medical centre in the
US. Drug Saf. 2010;33(10):879-88. PMID: 20812772 DOI: 10.2165/11532340-000000000-00000

16. Taegtmeyer AB, Kullak-Ublick GA, Widmer N, Falk V, Jetter A. Clinical usefulness of electronic drug-drug interaction checking in the care of cardiovascular surgery inpatients. Cardiology. 2012;123(4):219-22. PMID: 23208189 DOI: 10.1159/000343272

17. Sharma S, Chhetri HP, Alam K. A study of potential drugdrug interactions among hospitalized cardiac patients in a teaching hospital in Western Nepal. Indian J Pharmacol. 2014;46(2):152-6. PMID: 24741184 DOI: 10.4103/02537613.129303

18. Risch SC, Groom GP, Janowsky DS. Interfaces of psychopharmacology and cardiology-part one. J Clin Psychiatry. 1981;42(1):23-34. PMID: 6109716

19. Cruciol-Souza JM, Thomson JC. Prevalence of potential drug-drug interactions and its associated factors in a Brazilian teaching hospital. J Pharm Pharm Sci. 2006;9(3):427-33. PMID: 17207423

20. Ojeifo O, Wiviott SD, Antman EM, Murphy SA, Udell JA, Bates ER, et al. Concomitant administration of clopidogrel with statins or calcium-channel blockers: insights from the TRITON-TIMI 38 (trial to assess improvement in therapeutic outcomes by optimizing platelet inhibition with prasugrel-thrombolysis in myocardial infarction 38). JACC Cardiovasc Interv. 2013;6(12):1275-81. PMID: 24239201 DOI: 10.1016/j.jcin.2013.06.014

21. Pelliccia F, Rollini F, Marazzi G, Greco C, Gaudio C, Angiolillo DJ. Drug-drug interactions between clopidogrel and novel cardiovascular drugs. Eur J Pharmacol. 2015;765:332-6. PMID: 26341013 DOI: 10.1016/j.ejphar.2015.08.059

22. Manolis AS, Tzeis S, Andrikopoulos G, Koulouris S, Melita $\mathrm{H}$. Aspirin and clopidogrel: a sweeping combination in cardiology. Curr Med Chem Cardiovasc Hematol Agents. 2005;3(3):203-19. PMID: 15974885

23. Sarafoff N, Byrne RA, Sibbing D. Clinical use of clopidogrel. Curr Pharm Des. 2012;18(33):5224-39. PMID: 22724411 